\title{
Central nervous system in motor neuron disease
}

\section{Andrew Eisen}

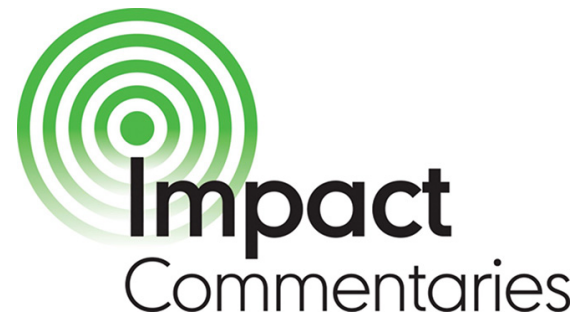

Neurodegenerative

syndromes, including Amyotrophic lateral sclerosis (ALS), are complex polygenic disorders resulting in multisystem impairment of neocortical network connectivity. Specific to ALS is dysfunction of the unique human corticomotoneuronal system, which is the basis of many early features of ALS, a singularly human disorder. Early deficits include loss of vocalisation requiring complex respiration, impaired fractionation of digits and thumb opposability, difficulty with upright walking with ability to navigate uneven and tricky surfaces while erect, and as part of Frontotemporal demention (FTD), impaired language and associated socialisation. ${ }^{1}$ The hallmark TAR DNA-binding protein 43 (TDP-43) pathology, seen in $>95 \%$ of patients with ALS, is largely restricted to corticofugal projecting neurons. This when taken together with sophisticated MRI imaging and threshold tracking using transcranial magnetic stimulation convincingly points to a cortical origin of ALS. ${ }^{2}$

It has been almost 50 years since Betty Brownell published 'the Central nervous system in motor neuron disease'. The 45 cases described is the second largest series with extensive clinical-pathological correlations reported up to $1970 .^{3}$

Doris Betty Brownell, known as Betty to her friends (figure 1), was born in 1925 into a Huguenot family of Dubliners, who all had distinguished academic passages through Trinity College, Dublin, from which she qualified in 1950. Betty spent 2 years at the Whittington Hospital as Registrar in Pathology, subsequently returning to Oxford in 1956 as Lecturer in Pathology. A succession of papers began in 1962 largely concerned with muscle and peripheral nerve neuropathology.

Up to that time, neuropathology had largely been done by general pathologists.

Correspondence to Dr Andrew Eisen, Division of Neurology, Department of Medicine, University of British Columbia, Vancouver, BC V1V 1V7, Canada; eisen@mail.ubc.ca
Brownell B, Oppenheimer DR, Trevor Hughes J. The central nervous system in motor neuron disease. J Neurol Neurosurg Psychiatry 1970;33:338-57.

Indeed, the first people to show special interest in the brain were typically pathologists attached to lunatic asylums, having access to the brains of patients with neurological abnormalities.

Due to Betty Brownell's passion, who in the $1970 \mathrm{~s}$ started a neuropathological department in Bristol, and Marion Smith, her contemporary at the National Hospital for Nervous Diseases, there was a movement in Britain to establish neuropathology as its own discipline. Late in life, she married J Trevor Hughes, a coauthor on the paper and a distinguished pathologist. Although now elderly he continues to enjoy an eventful, intellectual life in Oxford. Sadly Betty died of ovarian cancer shortly after their marriage.

All of Brownell's cases showed loss of spinal motor neurons, but pyramidal tract abnormalities were variable, with a number lacking any abnormalities. This resulted in her preference of 'motor neurone disease', since it applies to degeneration of either lower or upper motor neurons, or both. Furthermore, there was inconsistency in the severity of myelin pallor seen in the descending motor tracts at different spinal levels (cervical vs thoracic vs lumbar). Given this she was unable to conclude the currently increasing acceptance of a primary 'corticofugal' process in the pathogenesis of ALS. ${ }^{2}$

She recognised ALS to be a multisystem degeneration extending beyond upper and lower motor neurons, and considered it was a 'prominent band' in a wide spectrum of subacute and chronic multiple system atrophies. She identified variable involvement of the basal ganglia. Dysfunction of frontostriatal networks likely contributes to ALS-neuropsychological impairment, dominated by executive dysfunction, apathy and deficits in social cognition, all prominent in ALS-FTD.

Brownell also identified callosal involvement in a number of her cases. In fact, this is is a consistent feature of ALS and is independent of clinical upper motor neuron deficits. It may reflect independent bilateral cortical involvement or interhemispheric spread of pathology. There is a predominantly rostral corticospinal tract involvement, which further supports the concept of independent cortical degeneration. ${ }^{4}$

Her study did not make note of cerebellar involvement or its connections; however, ubiquitinated forms of TDP-43 and ubiquitinated p62-positive inclusions are frequently observed in the cerebellum of ALS, and functional MRI, voxelbased morphometry and diffusion-tensor imaging have shown functional and structural cerebellar abnormalities. Cerebellar involvement occurs particularly in ALS-FTD overlap.

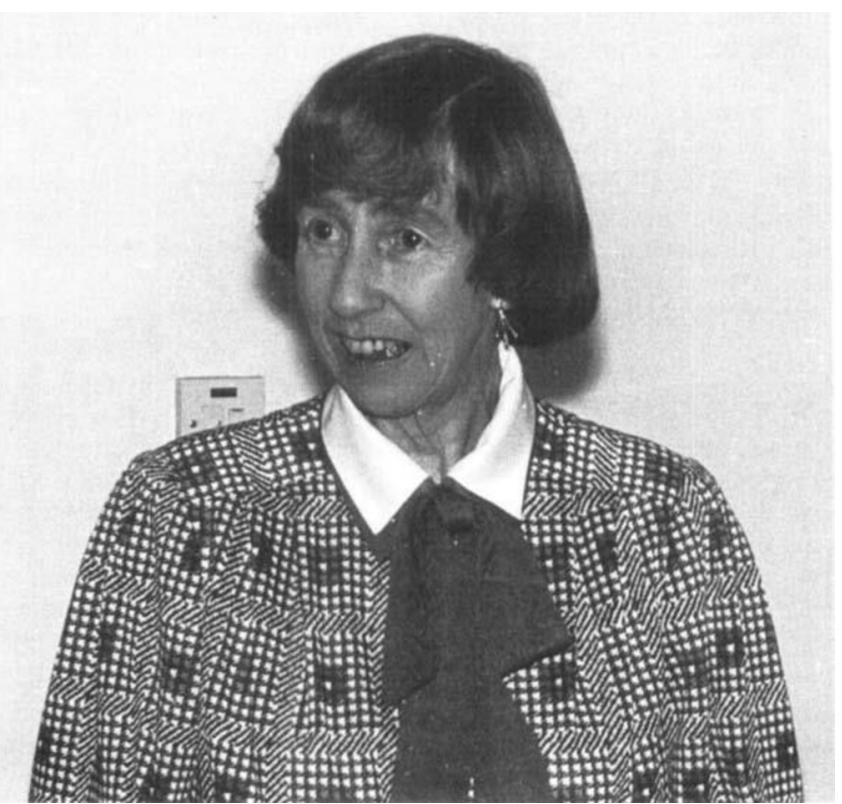

Figure 1 Dr Doris Betty Brownell, who worked tirelessly to establish neuropathology as a specialty in its own right in the UK. 
In terms of pathogenesis, Brownell questioned whether classic motor neuron disease may be part of a spectrum of disorders including transmissible spongiform encephalopathies, typified by Jakob-Creutzfeldt disease in which the infectious agent consists of aggregates of misfolded prion protein (PrP). In more than 95\% of familial and sporadic ALS, there is deposition of insoluble aggregated, phosphorylated and cleaved TDP-43 protein, acting as a misfolded 'prion-like' protein with spreading of toxic aggregates between cells. ${ }^{5}$ Remarkably, TDP-43 lesions develop only in structures that are under the direct control of corticofugal projections, supporting the idea that the driving force behind the origins of the TDP-43 pathology must reside in the cerebral cortex itself, beginning in the neocortical motor fields, and mediated via corticofugal axons with possible anterograde transport of toxic TDP-43 molecules.

Brownell's much cited paper was published 2 years after I was appointed to the Staff of the Montreal Neurological
Institute (MNI), McGill University, where I started its first electromyography (EMG) laboratory. Motor neuron disease was then a low priority at the Montreal Neurological Institute (MNI), partly because of the dominance of epilepsy that Wilder Penfield had fostered, but maybe also because of the uniformly fatal outcome of ALS. At the time (1970) EMG laboratories were entirely lower motor neuron-centric, so it is surprising that Brownell so keenly recognised the importance of the brain in ALS when few others did, and in this we are 'kindred spirits'. My own explorations regarding ALS and the motor cortex go back 30 years, and I remain firmly of the opinion that ALS is a unique disorder primarily affecting the human brain.

\section{Contributors I am the sole contributor.}

Funding The author has not declared a specific grant for this research from any funding agency in the public, commercial or not-for-profit sectors.

Competing interests None declared.

Patient consent Not required.

Provenance and peer review Commissioned; internally peer reviewed. (c) Article author(s) (or their employer(s) unless otherwise stated in the text of the article) 2018. All rights reserved. No commercial use is permitted unless otherwise expressly granted.

A Check for updates

To cite: Eisen A. J Neurol Neurosurg Psychiatry 2018:89:901-902

Received 15 February 2018

Accepted 27 February 2018

Published Online First 21 April 2018

J Neurol Neurosurg Psychiatry 2018;89:901-902. doi:10.1136/jnnp-2018-318186

\section{REFERENCES}

1 Eisen A, Kiernan M, Mitsumoto H, et al. Amyotrophic lateral sclerosis: a long preclinical period? J Neurol, Neurosurgery \& Psychiatry 2014;85:1232-8.

2 Eisen A, Braak H, Del Tredici K, et al. Cortical influences drive amyotrophic lateral sclerosis. J Neurol Neurosurg Psychiatry 2017:88:917-24.

3 Brownell B, Oppenheimer DR, Hughes JT. The central nervous system in motor neurone disease. J Neurol Neurosurg Psychiatry 1970;33:338-57.

4 Filippini N, Douaud G, Mackay CE, et al. Corpus callosum involvement is a consistent feature of amyotrophic lateral sclerosis. Neurol 2010;75:1645-52.

5 Bräuer S, Zimyanin V, Hermann A. Prion-like properties of disease-relevant proteins in amyotrophic lateral sclerosis. J Neural Transm 2018. Epub ahead of print. 